\title{
Comparison of ultrastructure, pollen tube growth pattern and starch content in developing and abortive ovaries during the progamic phase in hazel
}

\author{
Jianfeng Liu*, Huidi Zhang, Yunqing Cheng, Ju Wang, Yixin Zhao and Wanting Geng
}

Department of Life Science, College of Life Sciences, Jilin Normal University, Siping, China

Edited by:

Diego Rubiales, Consejo Superior de Investigaciones Cientificas, Spain

\section{Reviewed by:}

Abu Hena Mostafa Kamal,

Chungbuk National University,

South Korea

Antonio Castro, Consejo Superior de

Investigaciones Científicas, Spain

\section{*Correspondence:}

Jianfeng Liu, Department of Life

Science, College of Life Sciences, Jilin Normal University, Haifeng

Street 1301, Tiexi District, Siping 136000, Jilin Province, China

e-mail: jianfengliu1976@163.com

\section{HIGHLIGHTS}

- In an abortive ovary of hazel, an integument seldom differentiated and a mature embryo sac never developed.

- In an abortive ovary of hazel, pollen tube growth was arrested at the style base about 40 days after blooming. Thus, fertilization of the ovule was precluded.

- Ovary abortion in the four hybrid cultivars was indicated to be associated with insufficient resource availability to support fruit set by all flowers, whereas ovary abortion in $\mathrm{C}$. heterophylla was at least partly determined by pollen availability.

In Northeast China, a high frequency of ovary abortion contributes to serious losses in yield of hazelnut. The development of pistillate inflorescences and fruit clusters of four large-fruited hybrid hazel cultivars and the small-fruited Corylus heterophylla were used to study ovary abortion and its possible causes during the progamic phase in hazel. The average number of pistillate (ANP) flowers per inflorescence and average number of fruit (ANF) per cluster of four hybrid hazel cultivars were 7.6-8.5 and 2.4-3.0 respectively; in C. heterophylla, its ANP and ANF was 5.8-6.2 and 3.5, respectively. The total drop varied from 50 to $67 \%$. Ovary abortion in hazel initiated from about 30 days after blooming. The percentage of abortive ovaries (PAO) in the four hybrid hazel cultivars ranged from 63 to $72 \%$, and was significantly higher than that of C. heterophylla (29-42\%). Only the abortive ovary ratio of $C$. heterophylla was significantly reduced after artificial pollination. Fruit number per cluster was positively and negatively correlated with yield and nut mass, respectively. In abortive ovaries, the diameter remained less than $2 \mathrm{~mm}$ during the entire fruit development, an integument seldom differentiated and a mature embryo sac never developed. In addition, pollen tube growth was arrested at the style base about 40 days after blooming. Thus, fertilization of the ovule was precluded. Compared with abortive ovary, starch content in developing ovary of four hybrid hazel cultivars and $C$. heterophylla were significantly higher. This study suggests that abortive ovary was incapable to finish fertilization process due to the absence of mature embryo sac and arrested pollen tubes, and this is likely associate with insufficient resource availability to support fruit set by all flowers in four hybrid hazel cultivars, whereas ovary abortion in $C$. heterophylla is at least partly determined by pollen availability.

Keywords: hazelnut, abortive ovary, pistillate inflorescence, fruit cluster, delayed fertilization

\section{INTRODUCTION}

Hazel (Corylus spp.) is the most widely distributed and economically important member of the Betulaceae family in China. The hazel forest area in China exceeds one million hectares, which is much higher than all other hazelnut-producing countries in the world. The northeast is the traditional hazelnut production region in China. Development of the hazelnut industry plays an important role in increasing farmers' income, especially in mountainous areas (Liu et al., 2012). Compared with yields of $600-1000 \mathrm{~kg} \mathrm{ha}^{-1}$ in Turkey, $2000-3000 \mathrm{~kg} \mathrm{ha}^{-1}$ in Italy and
$1700-2500 \mathrm{~kg} \mathrm{ha}^{-1}$ in the United States (Aydinoglu, 2013), yields in China are less than $450 \mathrm{~kg} \mathrm{ha}^{-1}$. Thus, investigating the factors responsible for the low yields and applying measures to enhance yields are important for development of the hazelnut industry in China.

Two Corylus L. species are indigenous to Europe. The European hazel, C. avellana L., is widely distributed and the Turkish hazel, C. colurna L., is restricted to the Balkans, Romania and northern Turkey (Thompson et al., 1996). European hazel was introduced to northeast China in the twentieth century. 
However, extremely low winter temperatures in Northeast China present an insurmountable barrier to cultivation of hazel species, which originate from temperate areas. Corylus heterophylla Fisch. ex Besser and its hybrids with European hazel (hybrid hazel; C. heterophylla $\times$ C. avellana) are the most important Corylus germplasm in China. The yields of hybrid cultivars account for more than $90 \%$ of hazelnut production in China. In addition, their excellent cold resistance characteristics ensure their dominance of hazelnut production in China in the short term.

Normal pollination and fertilization is a prerequisite for development of full-sized fruit in hazel. The fact that all pollinated fruits do not produce an edible kernel is a common phenomenon (Akiko and Hiroshi, 2006). Abortive ovaries of hazel flowers are incapable of developing into fruits and are destined to drop or wither. Ovary abortion varies greatly with year, cultivar, individual tree, branch, and shoot, and even among and within inflorescences (Fabbri et al., 2004; Martin and Sibbett, 2005). Ovary abortion of olive (Olea europaea L.) occurs early in flower development, mostly 30-40 days before blooming (Cuevas et al., 1999; Reale et al., 2006). Hazel species show unique delayed fertilization characteristics and ovary abortion is initiated several months after pollination (Beyhan and Marangoz, 2007). The average number of functional ovaries in one hazel inflorescence is $40-60 \%$ for the Tombul cultivar and $40-55 \%$ for the Palaz cultivar (Germain, 1994; Beyhan and Marangoz, 2007). Beyhan and Odabaş (1995) reported that 45-60\% of the ovaries of hazel are abortive. Thus, only a small percentage of pollinated pistils of hazel develop into normal edible fruit (Thompson, 1967; Beyhan and Marangoz, 2007). A high frequency of ovary abortion in hybrid hazel and C. heterophylla has been observed in China in recent years, causing serious yield losses. However, the characteristics of hazel ovary abortion and the possible causal factors remain unknown. Therefore, the objective of this study was to characterize and investigate the possible causes of ovary abortion in hazel, so as to provide a scientific basis for development of strategies to reduce or overcome the yield losses resulting from ovary abortion.

\section{MATERIALS AND METHODS \\ STUDY SITE AND PLANT MATERIAL}

The trial was conducted at two towns of Siping City (Jilin province, China), including Shanmen ( $3 \mathrm{~km}$ southeast of Siping) and Yehe (30 km southeast of Siping). The two experiment zones are located in the North Temperate Zone and have a continental monsoon climate. The elevation varies from 110 to $240 \mathrm{~m}$. The climate conditions of the two locations were very close. The annual average temperature and rainfall was $5.9^{\circ} \mathrm{C}$ and $572.8 \mathrm{~mm}$, respectively. The average frost-free period is 142 days, and May to September is major growth seasons for crops. Both of them belong to dark-brown soil type, and their $\mathrm{pH}$ varies from 5.4 to 6.6. In Shanmen, 20-year-old trees of four hybrid hazel cultivars ("Bokehong," "Dawei," "Jinling," and "Yuzhui") were used as study materials. The spacing within and between rows was 3 and $4 \mathrm{~m}$, respectively, and the tree height ranged from 2.5 to $3.0 \mathrm{~m}$. In Yehe, 8-year-old C. heterophylla trees were used as study materials. The spacing within and between rows was 2 and $3 \mathrm{~m}$, respectively, and the tree height ranged from 1.0 to $1.5 \mathrm{~m}$. Female inflorescences and young fruits were sampled every 1-5 days from mid-April to late August in 2012 and 2013. The samples destined for histological examination or fluorescence microscopy observation were fixed in FAA solution (70\% ethanol: glacial acetic acid: formalin, 18:1:1 [v/v/v]) for 3 days, then stored in $70 \%$ alcohol at $4^{\circ} \mathrm{C}$.

\section{MEASUREMENT OF DEVELOPMENT CHARACTERISTICS OF PISTILLATE FLOWERS AND FRUIT CLUSTER}

In both 2012 and 2013, more than 300 pistillate inflorescences from each of five germplasms were randomly sampled during the peak flowering period (mid-April). Every pistillate inflorescence was dissected with a scalpel and forceps, and the number of pistillate flowers per inflorescence and the percentage of pistillate flowers per inflorescence were recorded.

On April 1st of both years, pollen was collected from the hazel orchards and air-dried using the method described by Liu et al. (2012). After mixing equal amounts of pollen from each individual and pollen germination test on stigma of cultivar Dawei, artificial pollination was carried out in the peak flowering period (mid-April). Results of pollen germination test indicated that more than $75 \%$ pollen grains could germinate, while the germination ratio of fresh mixed pollen on fresh stigma of cultivar Dawei was about $86 \%$. Twelve trees consistent in height and growth were selected for each hybrid hazel cultivar and $C$. heterophylla, and more than 300 pistillate inflorescences of each individual were artificially pollinated with brush and marked with tags. Concurrently, more than 300 open-pollinated pistillate inflorescences were randomly selected and marked with tags (the control). The tagged pistillate inflorescences and fruit clusters were monitored every week to determine the frequency of abscission from pollination to fruit harvest. On August 20th of both years, all remaining and tagged fruit clusters were harvested. Average number of fruit (ANF) per cluster, average number of abortive ovary (ANAO) per cluster, and percentage of abortive ovaries (PAO) per cluster were calculated. Fruit set as percentage of total number of pistillate flowers per plant (FS) was calculated using the following formula: $F S=100 \% \times \sum$ (fruit number after pistillate inflorescences tagged)/(number of tagged pistillate inflorescences $\times$ number of pistillate flowers per inflorescence). After dissection of the fresh nut, the shell mass, kernel mass and total nut mass were measured without drying. The kernel ratio was calculated with the following formula: kernel ratio $=$ kernel mass $\times 100 \% /$ total nut mass.

\section{OBSERVATION OF POLLEN TUBE GROWTH, AND OVARY AND OVULE DEVELOPMENT IN DEVELOPING AND ABORTIVE FRUITS}

According to our previous histological examination, fertilization is completed about 60 days after blooming in hazel (Liu et al., 2012). In order to examine the relationship between pollen tube growth and ovary abortion, young pistillate inflorescences or fruit clusters of the hybrid hazel cultivar "Dawei" were collected to observe pollen tube growth and the anatomical structure of the ovary from 1 to 60 days after blooming. Pollen tubes in pistillate inflorescences or young fruit were stained with aniline blue ( $0.1 \mathrm{~g}$ aniline blue and $0.071 \mathrm{~g} \mathrm{~K}_{3} \mathrm{PO}_{4}$ per $100 \mathrm{ml}$ distilled water), after bare-handed sectioned or squashing preparation, the stained 
specimens were to observed with a DM AE31EF-INV-5000C fluorescent microscope (Mike Audi Industrial Group Co., Ltd., China) with a UV filter set using the method of Liu et al. (2013) with minor modifications, and these modifications included samples softened in $1.0 \mathrm{M}$ boiling $\mathrm{NaOH}$ solution for $10 \mathrm{~min}$ and neutralized in $0.1 \mathrm{M}$ acetic acid solution during pretreatment stage.

Paraffin section was carried out in order to compare the morphological difference between developing and abortive ovaries, and the protocol of dehydration, staining, paraffin embedding and section of pistillate inflorescences or young fruit followed the method of Liu et al. (2012) with minor modifications in the pretreatment stage as described above.

\section{STARCH ASSAYS IN DEVELOPING AND ABORTIVE OVARIES}

In 2013 and 2014, pistillate inflorescences or young fruit cluster of four hybrid hazel cultivars and C. heterophylla were collected on 30,40 , and 50 days after blooming in the same orchard mentioned above. After fetching samples to laboratory, developing and abortive ovaries were separated and stored in liquid nitrogen. About $0.1 \mathrm{~g}$ sample was homogenized in a liquid $\mathrm{N}_{2}$ precooled mortar to measure starch content by using a pestle. The sample pretreatment and analysis followed the method described by Castro and Clément (2007).

\section{STATISTICAL ANALYSIS}

Statistical analysis was carried out with ANOVA process of SAS version 8.01 (SAS Institute, Inc., Cary, NC, USA). Means were compared using LSD (least significant difference) $t$-test at the $5 \%$ level of significance. Values expressed as a percentage were arcsin-transformed before analysis.

\section{RESULTS}

\section{NUMBER OF PISTILLATE FLOWERS PER INFLORESCENCE}

The percentage and mean number of pistillate flowers per inflorescence for each hybrid hazel cultivar and C. heterophylla are summarized in Table 1. The number of pistillate flowers per inflorescence ranged from four to 16 for the four hybrid hazel cultivars and from two to 16 for $C$. heterophylla. The number of pistillate flowers per inflorescence did not show a uniform and random distribution or a normal distribution. Instead, certain numbers of pistillate flowers per inflorescence showed a high frequency. For the hybrid hazel cultivars, six, eight, and 10 pistillate flowers per inflorescence were the most frequent numbers and their sum accounted for more than $60 \%$ of the total number of inflorescences. The most frequent numbers of pistillate flowers per inflorescence for $C$. heterophylla were four or six, which together made up more than $40 \%$ of the total number of inflorescences. The average number of pistillate (ANP) flowers per inflorescence ranged from 5.8 (in C. heterophylla) to 8.5 (in "Dawei" and "Bokehong"). The mean value for C. heterophylla was significantly lower than those of the four hybrid hazel cultivars.

\section{PISTILLATE INFLORESCENCE AND FRUIT CLUSTER DROP IN OPEN-POLLINATED AND ARTIFICIALLY POLLINATED FLOWERS}

Pistillate inflorescence drop ratio, fruit cluster drop ratio and total drop ratio in open-pollinated and artificially pollinated flowers were calculated in 2012 and 2013. Among open-pollinated inflorescences, the percentage of pistillate inflorescence drop varied from 36 to $54 \%$, and the percentage of fruit cluster drop ranged from 4 to $27 \%$ (Table 2). Among the four hybrid hazel cultivars, no significant difference was observed in the percentage of total drop between open and artificial pollination. For C. heterophylla, the total drop after artificial pollination was significantly lower than those of the open-pollinated controls. Thus, artificial pollination significantly reduced total drop in C. heterophylla, but had no significant effect on total drop in the four hybrid hazel cultivars.

\section{FRUIT NUMBER PER CLUSTER AFTER OPEN AND ARTIFICIAL POLLINATION}

Fruit number per cluster did not show a uniform or random distribution pattern (Table 3). A minimum of one fruit per cluster

Table 1 | Number of pistillate flowers per inflorescence in four hybrid hazel cultivars and $C$. heterophylla.

\begin{tabular}{|c|c|c|c|c|c|c|c|c|c|c|c|c|c|c|c|c|c|}
\hline Year & $\begin{array}{l}\text { Cultivar/ } \\
\text { species }\end{array}$ & \multicolumn{15}{|c|}{ Number of pistillate flowers per inflorescence ${ }^{1}$} & Average \\
\hline \multirow[t]{4}{*}{2012} & Dawei & $0^{b}$ & $0^{b}$ & $0.99^{c}$ & $5.94^{c}$ & $22.77^{b}$ & $10.89^{b c}$ & $20.79^{b}$ & $2.97^{\mathrm{C}}$ & $17.82^{b}$ & $2.97^{\mathrm{a}}$ & $5.94^{\mathrm{b}}$ & $2.98^{\mathrm{a}}$ & $0.99^{\mathrm{a}}$ & $1.98^{\mathrm{b}}$ & $2.97^{\mathrm{a}}$ & $8.52^{\mathrm{a}}$ \\
\hline & Bokehong & $0^{\mathrm{b}}$ & $0^{\mathrm{b}}$ & $0.56^{c}$ & $6.36^{\mathrm{c}}$ & $21.32^{b}$ & $9.92^{\mathrm{c}}$ & $21.34^{b}$ & $4.41^{\mathrm{b}}$ & $19.32^{\mathrm{a}}$ & $1.67^{\mathrm{b}}$ & $6.74^{\mathrm{a}}$ & $3.21^{\mathrm{a}}$ & $1.03^{\mathrm{a}}$ & $2.01^{\mathrm{b}}$ & $2.11^{\mathrm{b}}$ & $8.54^{\mathrm{a}}$ \\
\hline & Jinling & $0^{\mathrm{b}}$ & $0^{\mathrm{b}}$ & $1.24^{\mathrm{C}}$ & $5.11^{d}$ & $25.65^{a}$ & $11.32^{\mathrm{ab}}$ & $20.54^{b}$ & $5.81^{\mathrm{a}}$ & $13.76^{c}$ & $3.01^{a}$ & $7.21^{\mathrm{a}}$ & $2.04^{b}$ & $0.45^{c}$ & $2.21^{a}$ & $1.65^{c}$ & $8.30^{\mathrm{ab}}$ \\
\hline & Yuzhui & $0^{b}$ & $0^{b}$ & $2.43^{b}$ & $8.10^{\mathrm{b}}$ & $26.87^{a}$ & $12.26^{\mathrm{a}}$ & $26.21^{a}$ & $3.11^{\mathrm{c}}$ & $14.21^{c}$ & $1.76^{b}$ & $3.22^{\mathrm{c}}$ & $1.07^{\mathrm{c}}$ & $0.76^{b}$ & $0^{c}$ & $0^{e}$ & $7.60^{\mathrm{b}}$ \\
\hline \multirow[t]{5}{*}{2013} & Dawei & $0^{\mathrm{b}}$ & $0^{b}$ & $1.24^{\mathrm{C}}$ & $5.79^{d}$ & $20.37^{b}$ & $12.42^{\mathrm{a}}$ & $21.37^{a}$ & $4.54^{b}$ & $15.39^{b}$ & $4.65^{a}$ & $5.54^{b}$ & $2.92^{b}$ & $2.16^{a}$ & $1.94^{c}$ & $1.67^{c}$ & $8.50^{a}$ \\
\hline & Bokehong & $0^{\mathrm{b}}$ & $0^{\mathrm{b}}$ & $0.43^{c}$ & $6.53^{c}$ & $22.51^{a}$ & $9.53^{c}$ & $21.49^{a}$ & $3.99^{c}$ & $20.46^{a}$ & $2.07^{d}$ & $5.51^{b}$ & $3.80^{\mathrm{a}}$ & $1.52^{\mathrm{b}}$ & $1.07^{d}$ & $1.09^{d}$ & $8.41^{a}$ \\
\hline & Jinling & $0^{\mathrm{b}}$ & $0^{b}$ & $1.09^{c}$ & $6.24^{\mathrm{cd}}$ & $23.99^{a}$ & $10.76^{b}$ & $19.34^{b}$ & $6.07^{\mathrm{a}}$ & 14.03 & $3.28^{\mathrm{b}}$ & $6.94^{\mathrm{a}}$ & $1.91^{\mathrm{C}}$ & $1.27^{\mathrm{c}}$ & $2.37^{a}$ & $2.71^{\mathrm{a}}$ & $8.45^{a}$ \\
\hline & Yuzhui & $0^{\mathrm{b}}$ & $0^{\mathrm{b}}$ & $3.07^{b}$ & $8.27^{b}$ & $23.32^{\mathrm{a}}$ & $11.34^{b}$ & $20.68^{a b}$ & $4.35^{b}$ & $15.47^{b}$ & $2.37^{\mathrm{c}}$ & $3.33^{c}$ & $2.71^{\mathrm{b}}$ & $0.94^{d}$ & $2.20^{b}$ & $1.95^{b}$ & $8.10^{\mathrm{a}}$ \\
\hline & C.heterophylla & $0.97^{a}$ & $9.47^{a}$ & $25.44^{\mathrm{a}}$ & $10.29^{a}$ & $15.29^{c}$ & $12.89^{\mathrm{a}}$ & $10.99^{c}$ & $2.14^{d}$ & $6.09^{d}$ & $1.37^{e}$ & $1.21^{d}$ & $1.97^{\mathrm{c}}$ & $0^{e}$ & $0.94^{d}$ & $0.94^{d}$ & $5.88^{b}$ \\
\hline
\end{tabular}

${ }^{1}$ Values are the percentage in each category of the total number of inflorescences sampled. The percentage values were arcsin-transformed before the analysis of variance. Values within the same column and year followed by different lowercase letters are significantly different at $P \leq 0.05$ as indicated by LSD test. 
Table 2 | Pistillate inflorescence and fruit cluster drop after open (Control) and artificial pollination (AP) in four hybrid hazel cultivars and $C$. heterophylla.

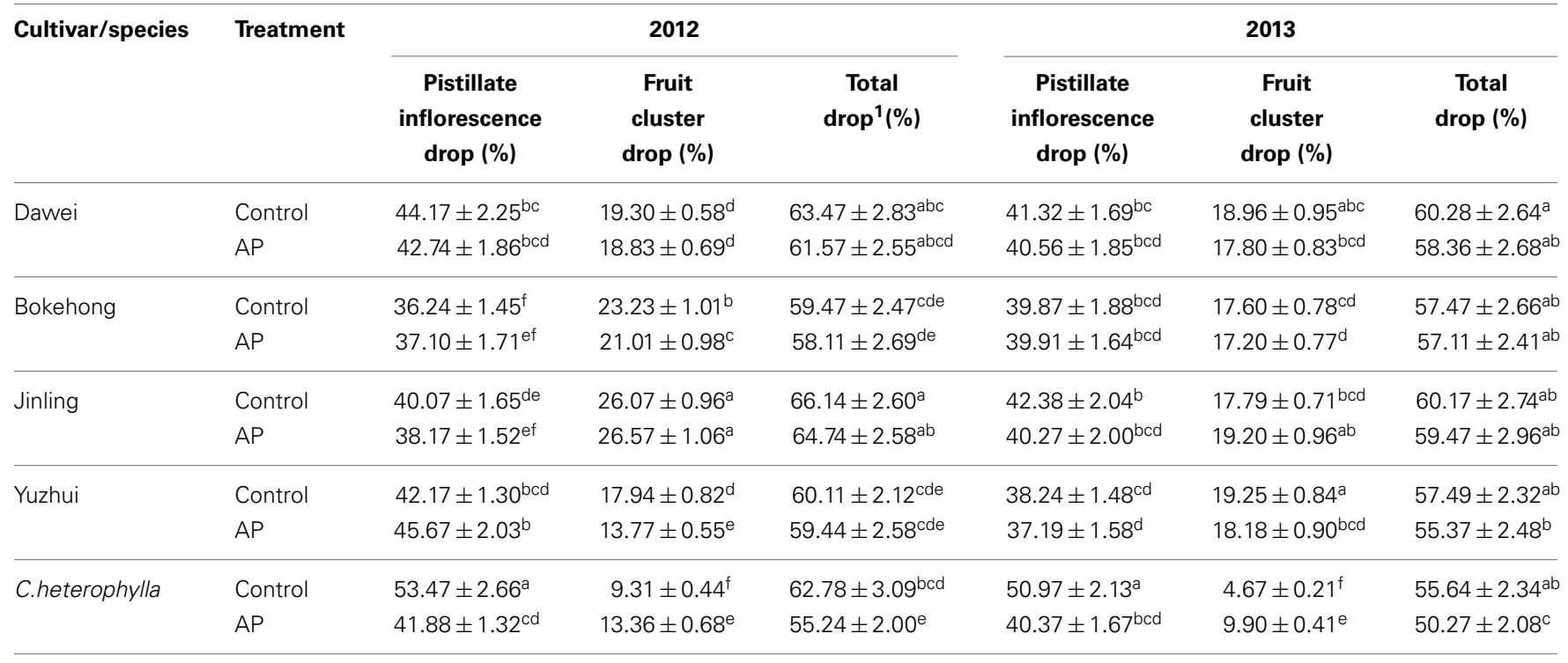

${ }^{1}$ The sum of pistillate inflorescence and fruit cluster drop. Values within the same column followed by different lowercase letters are significantly different at $P \leq 0.05$ as indicated by LSD test.

was recorded for all individuals. A maximum number of five to six fruit per cluster was recorded for "Dawei" and "Yuzhui" and six to seven for "Bokehong" and "Jinling" in the 2 years, respectively. For "Dawei" and "Yuzhui," the percentage of clusters carrying more than three fruits per cluster was low, whereas the percentage of clusters with one to three fruits was comparatively higher. For "Bokehong" and "Jinling," two to four were the most frequent numbers of fruits per cluster. Fruit clusters with three or four nuts showed the highest percentage frequency in C. heterophylla. The average fruit number per cluster of the four hybrid cultivars ranged from 2.1 to 3.1 , which was significantly lower than that of C. heterophylla.

In open-pollinated inflorescences, the percentage abortive ovaries among the four hybrid hazel cultivars ranged from 63 to $72 \%$ and were significantly higher than that of C. heterophylla. Artificial pollination had no significant effect on ANF per cluster, ANAOs per cluster and PAO per cluster in each cultivar. However, artificial pollination significantly promoted ANF, whereas ANAO and PAO were significantly lowered in C. heterophylla. Thus, artificial pollination had no significant effect on the frequency of abortive ovaries in the hybrid hazel cultivars, but significantly reduced that in $C$. heterophylla.

In addition to the high frequency of pistillate inflorescence drop and young fruit drop in four hybrid hazel cultivars (58 67\%), the development of most pollinated ovaries stopped soon after pollination. For instance, number of pistillate flowers per inflorescence and ANF per cluster was about 8.5 (Table 1) and 2.4 (Table 3) respectively in cultivar Dawei. Therefore, the percentage of pistillate flowers that set fruit per plant (FS) was pretty low. Among the four hybrid hazel cultivars, FS ranged from 8 to $12 \%$. Artificial pollination had no significant effect on FS. FS in C. heterophylla was much higher than that of the four hybrid hazel cultivars. Artificial pollination significantly increased FS in
C. heterophylla by promoting the proportion of pistillate flowers that set fruit. Thus, fruit drop was significantly reduced by artificial pollination in C. heterophylla.

\section{NUT MASS CHARACTERISTICS, YIELD PER CLUSTER, AND KERNEL RATIO}

Fruit fresh biomass characteristics of open-pollinated and artificially pollinated clusters carrying the same number of fruit were compared. Artificial pollination had no significant effect on nut biomass. Therefore, only nut biomass and related traits of openpollinated clusters are shown in Table 4 . The number of fruit per cluster increased, whereas shell mass, kernel mass and total nut mass tended to decrease. Thus, fruit number per cluster was inversely related to total nut mass of an individual fruit cluster. In contrast, the total yield per cluster was directly related to fruit number per cluster. Nut size was much smaller in C. heterophylla than those of the hybrid hazel cultivars. The total nut mass of the hybrid hazel cultivars was triple that of $C$. heterophylla. The kernel ratio of the four hybrid hazel cultivars ranged from 0.38 to 0.50 . These results indicated that the fruit number per cluster was not related to the kernel ratio. The kernel ratio of $C$. heterophylla ranged from 0.30 to 0.39 and was slightly lower than those of the hybrid hazel cultivars.

\section{EXTERNAL MORPHOLOGY AND POLLEN TUBE GROWTH IN DEVELOPING AND ABORTIVE OVARIES DURING PROGAMIC PHASE}

About 30-40 days after blooming, the ovary visibly began to develop. At this stage, abortive ovaries were easily distinguished from developing ovaries (Figures 1A,B). The diameter of abortive ovaries remained less than $2 \mathrm{~mm}$ during the entire inflorescence and fruit development stages, which was much smaller than that of developing ovaries. About 60-70 days after blooming, abortive ovaries began to harden and wither (Figure 1C), whereas 


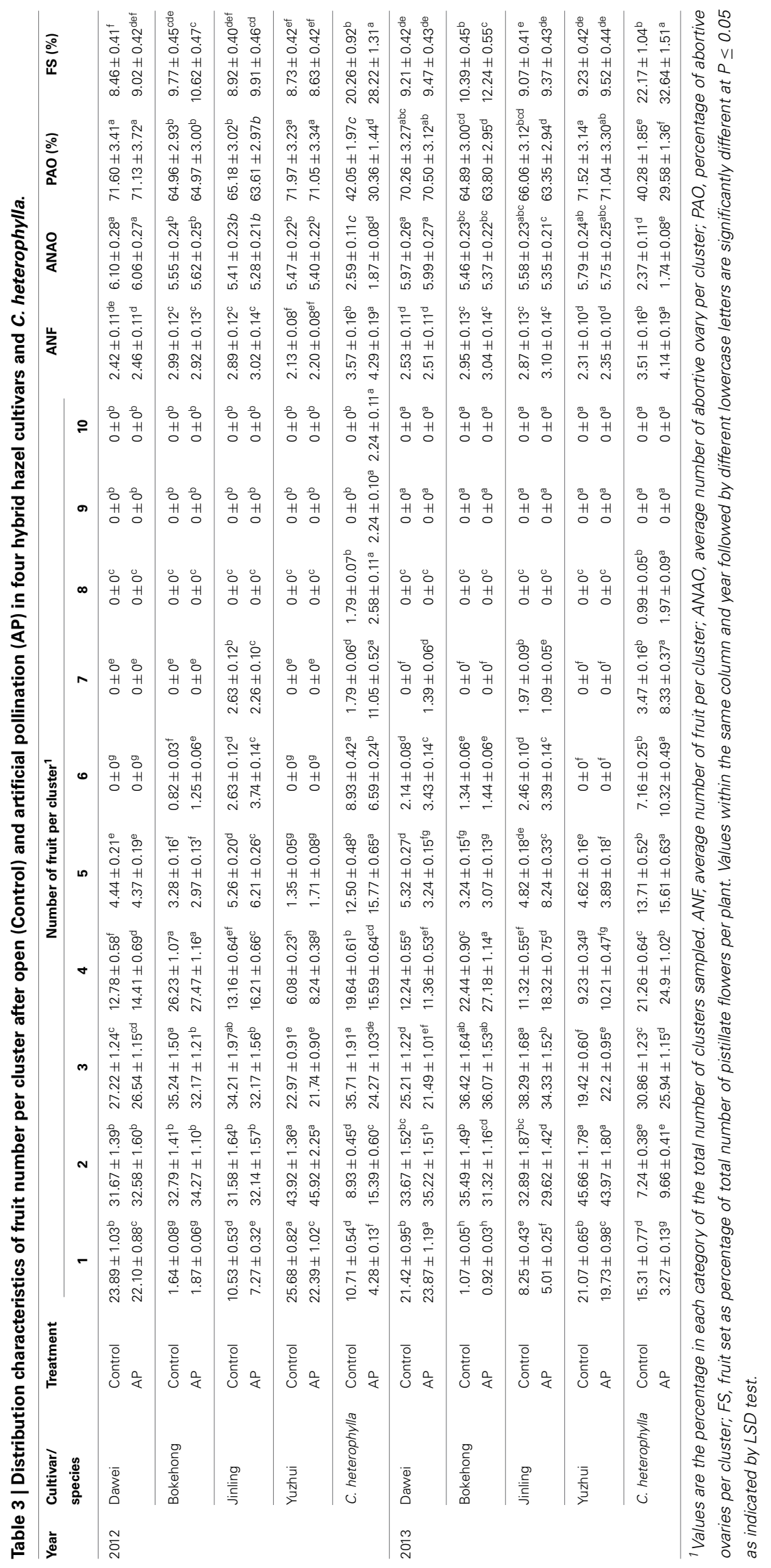


Table 4 | Nut fresh biomass characteristics, yield per cluster and kernel ratio after open pollination (Control).

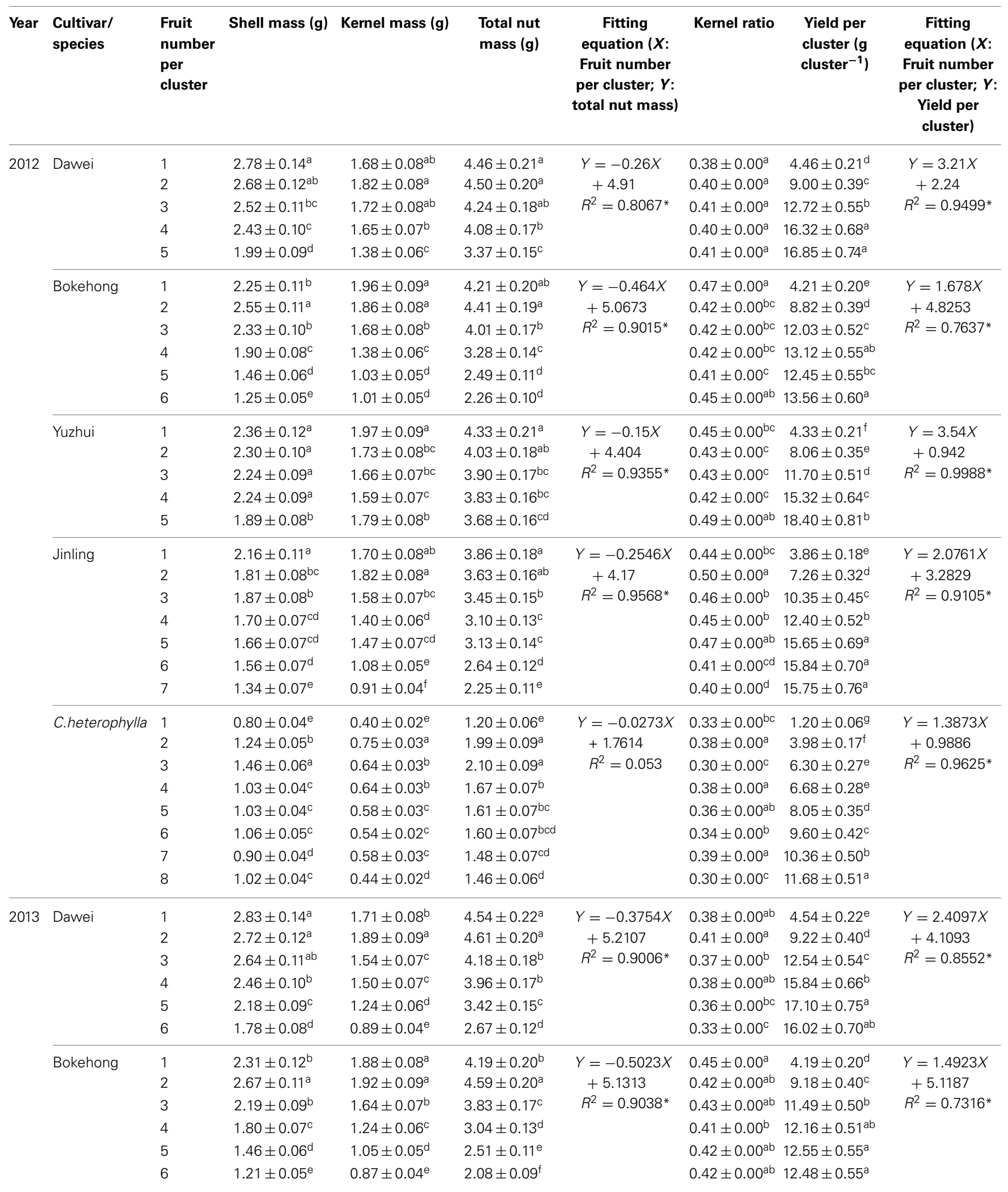

(Continued) 
Table 4 | Continued

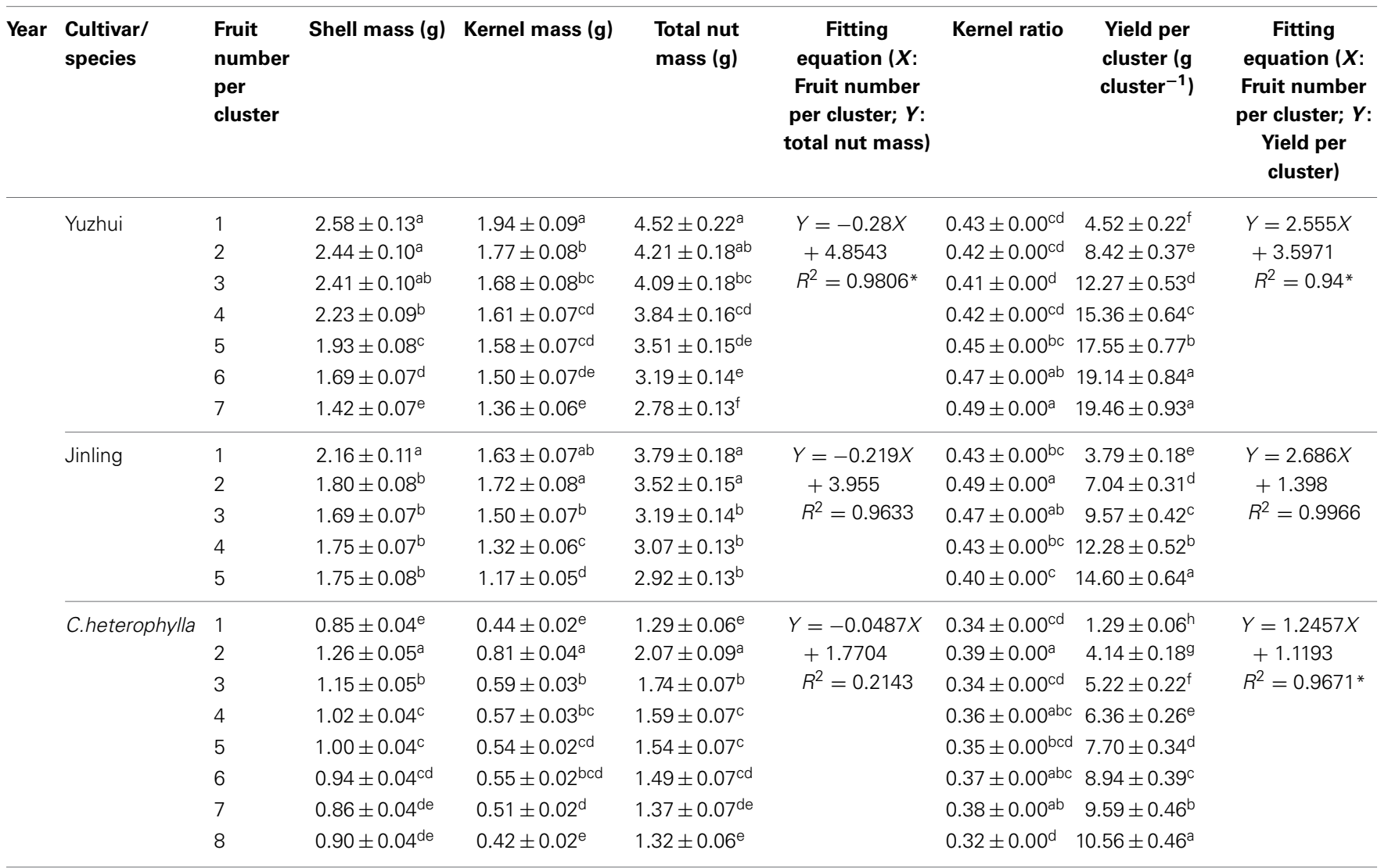

*Indicates a significant difference at the $P \leq 0.05$ level. Values within the same column and year for each cultivar/species followed by different lowercase letters are significantly different at $P \leq 0.05$ as indicated by $L S D$ test.

developing ovaries within the same fruit cluster continued to grow until harvest.

Soon after blooming and pollination, pollen grains germinated on the stigma. The pollen tubes grew to the style base within a few days (Figure 1D). Because no obvious ovary had developed at anthesis, the pollen tubes curled at the style base and awaited development of the ovary and ovules (Figure 1E) for about 20 days. About 40 days after blooming, pollen tubes maintain curly in the style (Figure 1F). Although smaller in diameter than developing ovaries, pollen tubes in abortive ovaries were observed to reach a similar location as in developing ovaries 40 days after blooming (Figure 1G). Two ovules were observed in a developing ovary by fluorescence microscopy 45 days after blooming. At this stage, pollen tubes in the style began to grow toward the developing ovule (Figure 1H). During the same stage, in the abortive ovary pollen tube growth was completely arrested at the style base until ovary withering and thus never grew beyond the style base (Figures 1I,K,M,O). A single pollen tube was observed to change direction and grew to the ovule in the developing ovary on 50th day after blooming (Figure 1J). This pollen tube passed though vicinity of the micropyle and stretched forward without entering the micropyle (Figure 1L). Finally, the pollen tube entered the embryo sac to release two sperm cells (Figure 1N) on the 60th day after blooming.

\section{ANATOMY OF ABORTIVE AND DEVELOPING OVARIES DURING PROGAMIC PHASE}

The ovary began to develop gradually after blooming. About 20 days after booming, an early ovary primordium was obvious (Figure 2A). The ovary primordium developed and differentiated further and an early rudimentary ovary had formed on about the 25th day after blooming (Figure 2B). The difference in diameter of developing and abortive ovaries was apparent on about the 30th day after blooming (Figures 2C,D). During this stage, ovules were not discernible in either ovary type (Figures 2C,D). In the developing ovary, a spherical ovule had developed in the approximate center of the ovary (Figure 2E) by about the 40th day after blooming. At the same stage, only a hemispherical ovule primordium had formed in the abortive ovary (Figure 2F). In the developing ovary, the ovule began to differentiate an integument and the embryo sac began to develop in the nucellus by the 50th day after blooming (Figure 2G). In the abortive ovary, an oval ovule had formed at the same stage but its differentiation had not begun (Figure 2H). A mature embryo sac in the developing ovary was observed on the 55th day after blooming (Figure 2I). No embryo sac was observed in the abortive ovary prior to it withering (Figure 2J). Soon after mature embryo sac formation, a spherical embryo was observed on about the 65th day after blooming (Figure $2 \mathbf{K}$ ). In brief, the 

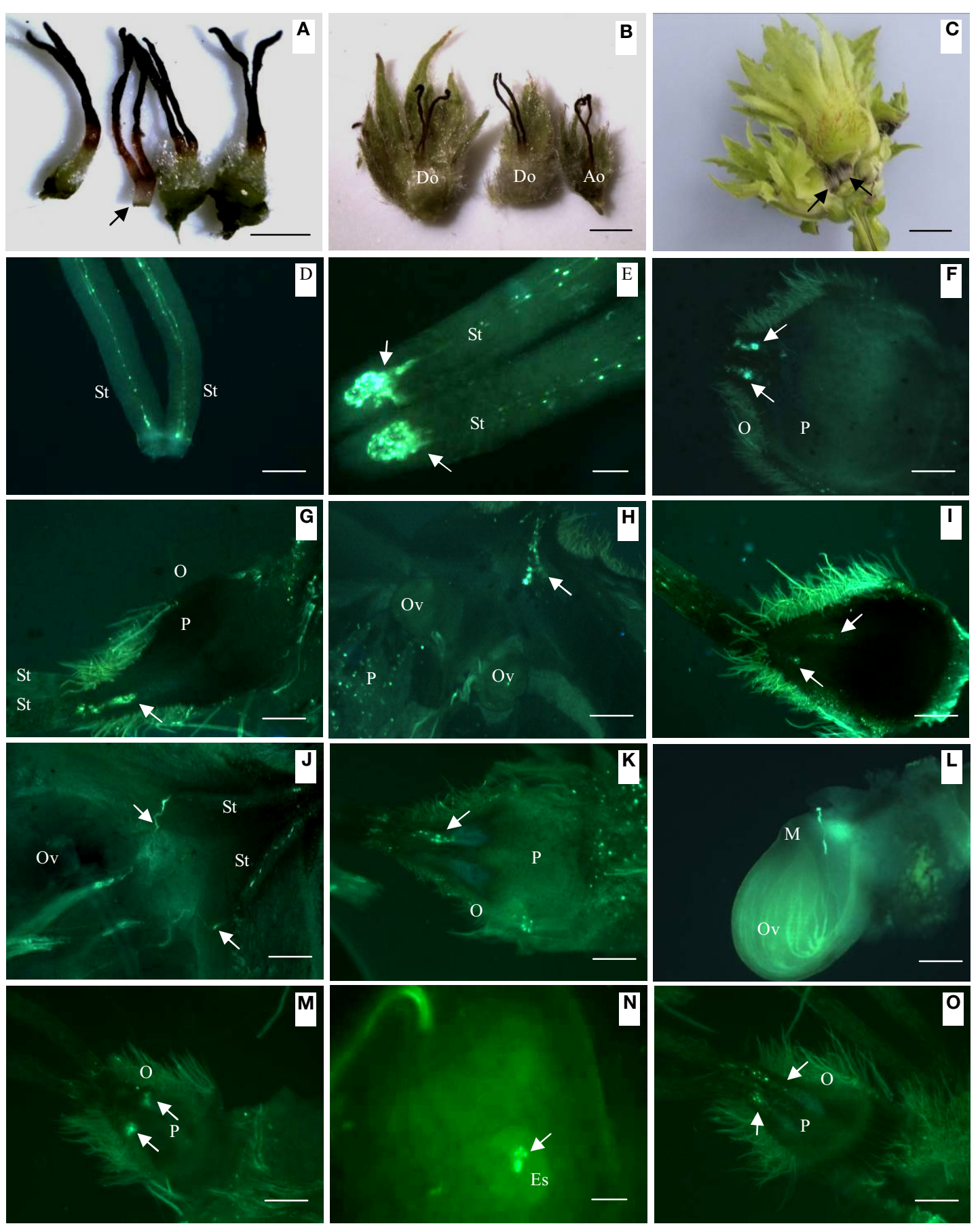

FIGURE 1 | Differences in external morphology and pollen tube growth in developing and abortive ovaries during the progamic phase. (A)

External morphology of abortive ovary (indicated by arrow) and developing ovary, 30 days after blooming. (B) Normally developing ovary (left and center) and abortive ovary (right), 40 days after blooming. (C) Normally developing fruit and abortive fruit in a fruit cluster, 65 days after pollination. Arrows indicate abortive ovaries. (D) Young pollen tubes in the style, 5 days after blooming. (E) Pollen tubes curled and arrested at the style base, showed by arrows, 20 days after blooming. (F) Pollen tubes growing into developing ovary, arrows showed pollen tubes, 40 days after blooming. (G) Pollen tubes (showed by arrow) growing into abortive ovary, 40 days after pollination. (H) Pollen tubes (showed by arrow) growing toward ovule, 45 days after pollination. (I) Pollen tubes arrested in abortive ovary (showed by arrow), 45 days after pollination. (J) Pollen tubes in style (showed by arrow) changed direction and grew toward ovule, 50 days after pollination. (K) Pollen tubes arrested in abortive ovary, 50 days after pollination. (L) Pollen tubes starting to penetrate ovule of developing ovary, 55 days after pollination. (M) Abortive ovary with Curled and arrested pollen tubes, 55 days after pollination. (N) Pollen tubes in developing ovary release two sperm cells in embryo sac, 60 days after blooming. (O) Abortive ovary with curled and arrested pollen tubes, 60 days after blooming. Key: Ao, abortive ovary; Do, developing ovary; Es, embryo sacs; $M$, micropyle; O, ovary; Ov, ovule; P, parenchyma; St, style; Scale bars: $\mathbf{A}, \mathbf{B}=1 \mathrm{~mm} ; \mathbf{C}=400 \mu \mathrm{m} ; \mathbf{D}=$ $300 \mu \mathrm{m} ; \mathbf{E}=100 \mu \mathrm{m} ; \mathbf{F}-\mathbf{O}=300 \mu \mathrm{m}$. 

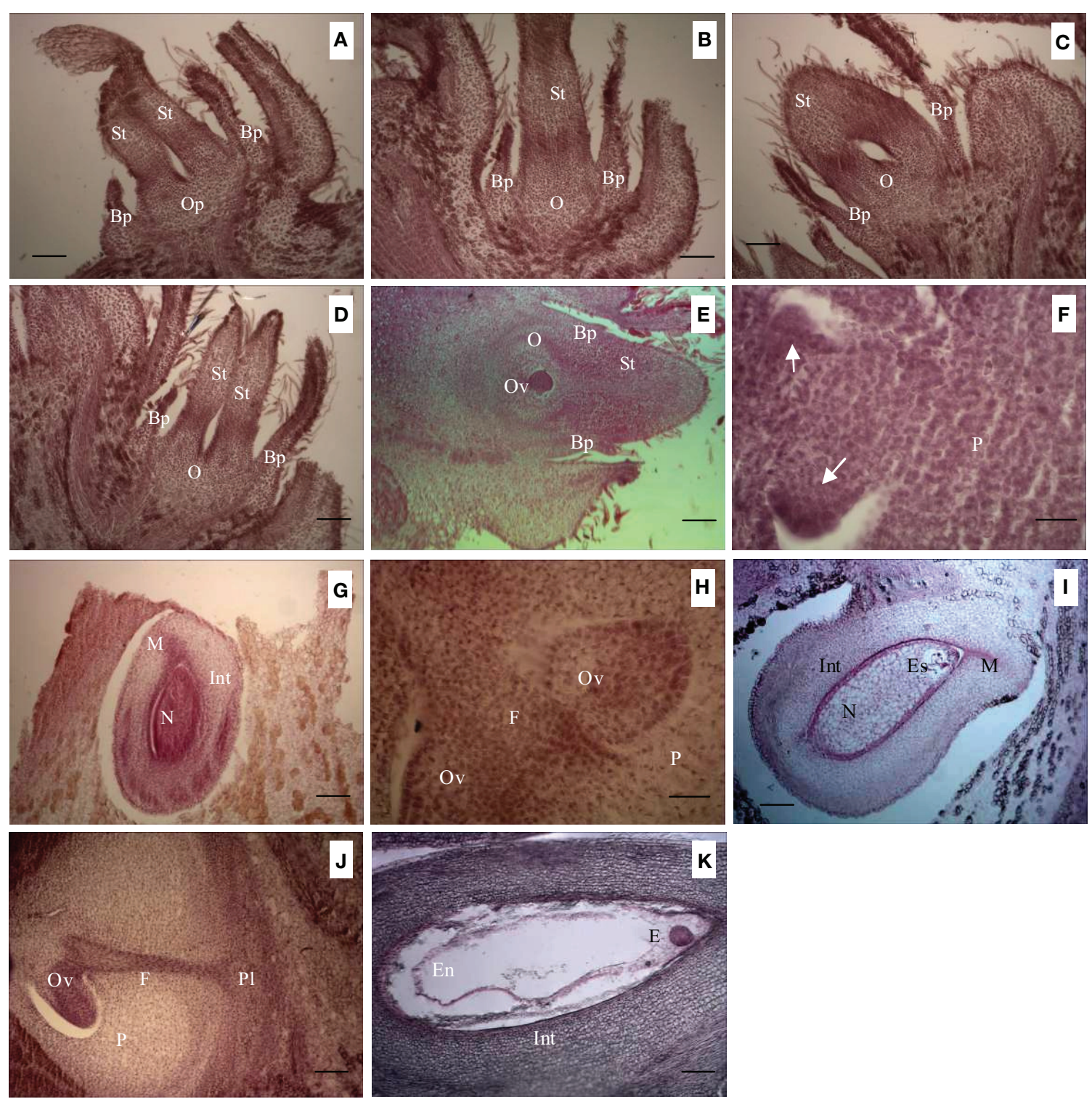

FIGURE 2 | Anatomical differences in abortive and young developing fruit during the progamic phase. (A) Early ovary primordium, 20 days after blooming. (B) Early rudimentary ovary, 25 days after blooming. (C) Developing ovary, 30 days after blooming. (D) Abortive ovary, 30 days after blooming. (E) Developing ovary with early ovule, 40 days after blooming. (F) Abortive ovary with early ovule primordia indicated by arrows, 40 days after blooming. (G) Ovule in developing ovary, 50 days after blooming. (H) Ovules in abortive ovary, 50 days after blooming. (I) Ovule with mature embryo sac in developing ovary, 55 days after blooming. (J) Ovule lacking differentiated embryo sac and nucellus in abortive ovary, 55 days after blooming. (K) Embryo in fertilized ovule of developing ovary, 65 days after blooming. Key: Bp, bract primordium; E, embryo; En, endosperm; Es, embryo sac; F, funiculus; Int, integument; $M$, micropyle; N, nucellus; Op, ovary primordium; O, ovary; Ov, ovule; P, parenchyma; PI, placenta; St, style. Scale bars: A,B $=100 \mu \mathrm{m} ; \mathbf{C}-\mathbf{E}=100 \mu \mathrm{m} ; \mathbf{F}=30 \mu \mathrm{m} ; \mathbf{G}=100 \mu \mathrm{m}$; $\mathbf{H}=30 \mu \mathrm{m} ; \mathbf{I}-\mathbf{K}=100 \mu \mathrm{m}$. development of abortive ovaries was much slower than that of normally developing ovaries. The diameter of abortive ovaries was maintained at $1-2.0 \mathrm{~mm}$ during its life cycle. Although an ovule developed to a certain degree in the abortive ovary, a mature ovule containing an embryo sac never developed. Subsequently, abortive ovaries began to dehydrate and wither. Thus, it was impossible for the ovule in an abortive ovary to be fertilized.

\section{COMPARISON OF STARCH CONTENT IN ABORTIVE AND DEVELOPING OVARIES DURING THE PROGAMIC PHASE}

Starch content in abortive and developing ovaries during the progamic phase was measured to clarify the relationship between ovary abortion and starch accumulation, and the results were showed in Table 5. In the year of 2013-2014, for the developing ovary, its starch content decreased from 30 to 50 days after blooming, while starch content in abortive ovary 
Table 5 | Starch content in ovaries of four hybrid hazel cultivars and C. heterophylla.

\begin{tabular}{|c|c|c|c|c|c|c|c|}
\hline Cultivar/species & Treatment & \multicolumn{3}{|c|}{2013} & \multicolumn{3}{|c|}{2014} \\
\hline \multirow[t]{2}{*}{ Dawei } & DO & $490.4 \pm 22.71^{b c}$ & $427.9 \pm 19.18^{a}$ & $350.4 \pm 17.01^{b}$ & $510.2 \pm 2.34^{a}$ & $452.6 \pm 20.16^{a}$ & $339.1 \pm 14.71^{b c}$ \\
\hline & $\mathrm{AO}$ & $217.7 \pm 10.38^{d}$ & $243.1 \pm 11.32^{c}$ & $200.4 \pm 9.33^{\mathrm{e}}$ & $247.0 \pm 11.67^{d}$ & $201.7 \pm 9.52^{\mathrm{de}}$ & $240.4 \pm 11.24^{e}$ \\
\hline \multirow[t]{2}{*}{ Jinling } & DO & $479.1 \pm 20.75^{c}$ & $390.4 \pm 16.77^{b}$ & $314.3 \pm 13.74^{c}$ & $450.2 \pm 19.19^{b c}$ & $352.1 \pm 15.35^{c}$ & $321.4 \pm 13.82^{c}$ \\
\hline & $\mathrm{AO}$ & $214.2 \pm 9.21^{d}$ & $211.5 \pm 9.32^{\mathrm{de}}$ & $230.4 \pm 9.22^{d}$ & $232.1 \pm 9.90^{\mathrm{de}}$ & $193.2 \pm 8.24^{e}$ & $201.2 \pm 8.56^{f}$ \\
\hline \multirow[t]{2}{*}{ Yuzhui } & DO & $534.7 \pm 20.32^{\mathrm{a}}$ & $430.5 \pm 16.01^{a}$ & $390.1 \pm 14.97^{a}$ & $504.1 \pm 19.06^{a}$ & $441.8 \pm 16.77^{a}$ & $376.1 \pm 14.39^{a}$ \\
\hline & $\mathrm{AO}$ & $195.0 \pm 8.25^{d}$ & $201.4 \pm 8.69^{e}$ & $214.3 \pm 9.09^{\mathrm{de}}$ & $207.2 \pm 8.86^{\mathrm{ef}}$ & $222.3 \pm 9.44^{d}$ & $184.5 \pm 7.89^{f}$ \\
\hline
\end{tabular}

$D O$ and $A O$ indicate developing ovary and abortive ovary respectively and DAB represents days after blooming. Values within the same column followed by different lowercase letters are significantly different at $P \leq 0.05$.

fluctuated within the specific limits. Compared with abortive ovary, starch content in developing ovary of four hybrid hazel cultivars and $C$. heterophylla were significantly higher without exception.

\section{DISCUSSION \\ RELATIONSHIP BETWEEN FRUIT NUMBER PER CLUSTER AND FRUIT \\ SIZE}

Fruit size is dependent mostly on cell number rather than cell size because cell number is the only factor determining sink strength (Bertin et al., 2002; Corelli-Grappadelli and Lakso, 2004). Mature fruit size is positively correlated with flower size and, particularly, ovary size at blooming (Rosati et al., 2009). During fruit development, fruit growth is mostly achieved through cell expansion (Rosati et al., 2012). Among several olive cultivars with different fruit sizes, genetic differences in fruit size appear to arise from differences in cell division patterns in the ovary (and probably in the whole flower) before blooming. The final fruit size, aside from genetic control, is also related to environmental and endogenous plant conditions that allow the genetic potential for growth to be achieved to a varying degree. European hazel (Corylus avellana L.) is a species with a peculiar floral biology characteristic. Petals, ovaries and ovules are absent in pistillate inflorescences at anthesis. Thus, the final nut size is not determined by flower size or cell number in the ovary at anthesis as is generally true. Compared with C. heterophylla, the nuts produced by the four hybrid hazel cultivars in the present study showed a much larger mass and size (Table 4), suggesting that genetic control plays an important role in determining the final nut size. In addition, fruit number per cluster was positively correlated with yield per cluster and thus was indicated to be a key factor determining sink strength in hazel (Table 4). Fruit number per cluster is always negatively correlated with nut mass (Table 4), implying limited sink strength had to sustain a greater number of fruit in a cluster and resulted in smaller nuts. Thus, a higher number of fruit per cluster was beneficial to increase the total yield but at the expense of a reduction in individual fruit size.

\section{POSSIBLE CAUSAL FACTORS FOR OVARY ABORTION IN HAZEL}

Many causes trigger the abortion of reproductive structures, including resource limitation (Herrera, 1991), pollen limitation (Burd, 1994), interaction between resource and pollen limitation (Juenger and Bergelson, 1997), damage caused by biological agents (Parker, 1987), adverse climatic conditions (Lee and Bazzaz, 1982) and the genetic background of the plant. Ovary abortion in olive appears to be related with resource competition among flowers; conditions that affect competition among flowers/fruits or that decrease available resources usually result in increased abortion (Reale et al., 2009). Pistil abortion is also known to be under genetic control and varies among cultivars (Lavee et al., 2002). Even genetic control can be explained with the competition theory (Rosati et al., 2011). Large-fruited cultivars tend to show a higher frequency of pistil abortion compared with small-fruited cultivars (Rosati et al., 2011). Compared with the small-fruited C. heterophylla, the PAO per cluster in the four large-fruited hybrid hazel cultivars was significantly higher (Table 3). Furthermore, the ANF per cluster was not promoted by artificial pollination in the hybrid hazel cultivars. Thus, a higher frequency of ovary abortion and an invariable ANF per cluster in the four hybrid cultivars might be associated with insufficient available resources for all flowers to develop. Competition within pistillate inflorescence might have led to early ovary abortion, which compensated for the limited resources. In C. heterophylla, artificial pollination significantly reduced the loss of yield caused by pistillate inflorescence drop and fruit drop (Table 2). In addition, the PAO and ANF per cluster of C. heterophylla were reduced and promoted by artificial pollination, respectively (Table 3 ). These results indicated that fruit set was at least partly determined by pollen availability. 
The reproductive success of Opuntia microdasys is simultaneously limited by the availability of nutrients and compatible pollen, the effect of florivory, and genetic incompatibility (Piña et al., 2007). In hazel, incompatibility is determined sporophytically and is controlled by a single locus with multiple alleles (Ma et al., 2013). Mixed pollen of five individuals was used in artificial supplementary pollinations to avoid incompatibility between the pollen and stigma in the present study. Fluorescence microscopic results indicated that pollen grains germinated well on the stigma and pollen tubes grew to the style base at early developmental stages of both developing and abortive ovaries. Subsequently, pollen tubes in the abortive ovary remained curled near the style base in the ovary and were unable to further and fertilize the ovule. A pollen tube in the developing ovary was observed to change direction and grow to the ovule on the 50th day after blooming. Thereafter, the pollen tube entered the integument and the embryo sac of the ovule on the 55th and 60th days after blooming, respectively. Thus, pollen incompatibility was not the factor leading to ovary abortion in hazel. Histological examination indicated that the ovule integument and embryo sac failed to develop in the abortive ovary prior to it withering. Deficiency of starch in flower of olive (Olea europaea L.) and within the ovule of apricot (Prunus armeniaca L.) might be involved in determining their abortion (Rodrigo and Herrero, 1998; Reale et al., 2006). Starch reserves in the ovary of avocado could play a significant role in the reproductive process (Alcaraz et al., 2010). Starch content in developing ovaries of four hybrid hazel cultivars and C. heterophylla was significantly higher than that in abortive ovary (Table 5), and the result was in accordance with that the reports mentioned above. Thus, the inability of pollen tubes to penetrate the ovule, the absence of a mature embryo sac in the ovule and deficiency starch were three important factors that led to ovary abortion. Nutrient addition increased seed production and decreased ovary abortion in Ipomopsis aggregata (Campbell and Halama, 1993). Whether spraying with nutrient solution before fertilization could reduce ovary abortion and increase final yield at harvest requires further research.

\section{CONCLUSIONS}

Besides loss due to pistillate inflorescence and fruit cluster drop, the development of most of the pistillates flower will stop and form abortive ovaries, and this process occurs during progamic stage of hazelnut. There are 5.8-8.5 pistillate flowers per pistillate inflorescence in four hybrid hazel cultivars and C. heterophylla (Table 1). At harvest, their fruit number per cluster ranged from 2.4 to 4.3 (Table 2). The PAO in the four hybrid hazel cultivars ranged from 63 to $72 \%$, and was significantly higher than that of C. heterophylla (29-42\%) (Table 3). The results of artificial pollination treatment indicated that only the abortive ovary ratio of $C$. heterophylla was significantly reduced following artificial pollination, and fruit number per cluster was positively and negatively correlated with yield and nut mass, respectively. Anatomy results of abortive ovary indicated that an integument seldom differentiated and a mature embryo sac never developed (Figure 1). Pollen tube growth of abortive ovaries showed that their pollen tube growth was arrested at the style base and was incapable to fertilize the ovules (Figure 2). Thus, fertilization of their ovules was precluded. Compared with abortive ovary, starch content in developing ovary of five tested germplasms were significantly higher. To conclude, abortive ovary was incapable to finish fertilization process due to the absence of mature embryo sac and arrested pollen tubes. For the four hybrid cultivars, abortive ovary was likely associated with insufficient resource availability to support fruit set by all flowers, whereas ovary abortion in $C$. heterophylla was at least partly determined by pollen availability.

\section{ACKNOWLEDGMENTS}

This work was funded by the following grants: National Natural Science Foundation of China (31370683 and 31070610), China Scholarship Council Project (201208220004), Science and Technology Project of Jilin Province (20130102052JC and 20140101145JC), and Scientific Items of Jilin Provincial Department of Education (2013202).

\section{REFERENCES}

Akiko, S., and Hiroshi, T. (2006). Delayed fertilization and pollen-tube growth in pistils of Fagus Japonica (Fagaceae). Am. J. Bot. 93, 1748-1756. doi: 10.3732/ajb.93.12.1748

Alcaraz, M. L., Hormaza, J. I., and Rodrigo, J. (2010). Ovary starch reserves and pistil development in avocado (Persea americana). Physiol. Plant. 140, 395-404. doi: 10.1111/j.1399-3054.2010.01410.x

Aydinoglu, A. C. (2013). Examining environmental condition on the growth areas of Turkish hazelnut (Corylus colurna L.). Afr. J. Biotechnol. 9, 6492-6502. doi: 10.5879/AJB10.400

Bertin, N., Gautier, H., and Roche, C. (2002). Number of cells in tomato fruit depending on fruit position and source-sink balance during plant development. Plant Growth Regul. 36, 105-112. doi: 10.1023/A:1015075821976

Beyhan, N., and Marangoz, D. (2007). An investigation of the relationship between reproductive growth and yield loss in hazelnut. Sci. Hortic. 113, 208-215. doi: 10.1016/j.scienta.2007.02.007

Beyhan, N., and Odabaş, F. (1995). "A research on the germination and the viability of pollen of some important hazelnut cultivars," in 2nd National Horticultural Congress of Turkey (Adana).

Burd, M. (1994). Bateman's Principle and plant reproduction: the role of pollen limitation in fruit and seed set. Bot. Rev. 60, 83-139. doi: 10.1007/BF02856594

Campbell, D. R., and Halama, K. J. (1993). Resource and pollen limitations to lifetime seed production in a natural plant population. Ecology 74, 1043-1051. doi: $10.2307 / 1940474$

Castro, A. J., and Clément, C. (2007). Sucrose and starch catabolism in the anther of Lilium during its development: a comparative study among the anther wall, locular fluid and microspore/pollen fractions. Planta 225, 1573-1582. doi: 10.1007/s00425-006-0443-5

Corelli-Grappadelli, L., and Lakso, A. N. (2004). Fruit development in deciduous tree crops as affected by physiological factors and environmental conditions. Acta Hortic. 636, 425-441.

Cuevas, J., Pinney, K., and Polito, V. S. (1999). Flower differentiation, pistil development and pistil abortion in olive. Acta Hortic. 474, 293-296.

Fabbri, A., Bartolini, G., Lambardi, M., and Kailis, S. G. (2004). Olive Propagation Manual. Collingwood, VIC: Landlinks Press.

Germain, E. (1994). The reproduction of hazelnut (Corylus avellana L.): a review. Acta Hortic. 351, 195-210

Herrera, C. M. (1991). Dissecting factors responsible for individual variation in plant fecundity. Ecology 72, 1436-1448. doi: 10.2307/1941116

Juenger, T., and Bergelson, J. (1997). Pollen and resource limitation of compensation to herbivory in scarlet gilia, Ipomopsis aggregata. Ecology 78, 1684-1695. doi: 10.1890/0012-9658(1997)078[1684:PARLOC]2.0.CO;2

Lavee, S., Taryan, J., Levin, J., and Haskal, A. (2002). The significance of crosspollination for various olive cultivars under irrigated intensive growing conditions. Olivae 91, 25-36.

Lee, T. D., and Bazzaz, F. A. (1982). Regulation of fruit and seed production in an annual legume, Cassia fasciculata. Ecology 63, 1363-1373. doi: 10.2307/ 1938864 
Liu, J. F., Cheng, Y. Q., Liu, C. M., Zhang, C. J., and Wang, Z. W. (2013). Temporal changes of disodium fluorescein transport in hazelnut during fruit development stage. Sci. Hortic. 150, 348-353. doi: 10.1016/j.scienta.2012. 12.001

Liu, J. F., Cheng, Y. Q., Yan, K., Liu, Q., and Wang, Z. W. (2012). The relationship between reproductive growth and blank fruit formation in Corylus heterophylla Fisch. Sci. Hortic. 136, 28-134. doi: 10.1016/j.scienta.2012. 01.008

Ma, Q. H., Wang, G. X., Liang, W. J., Chen, X., Liang, L. S., and Zhao, T. T. (2013). Progress on pollen-stigma compatibility in Corylus (hazelnuts): a review. J. For. Res. 24, 397-402. doi: 10.1007/s11676-013-0372-7

Martin, G. C., and Sibbett, G. S. (2005). "Botany of the olive," in Olive Production Manual, eds G. S. Sibbett, L. Ferguson, J. L. Coviello, and M. Lindstrand (Oakland, CA: University of California, Agriculture and Natural Resources), 15-19.

Parker, K. C. (1987). Seedcrop characteristics and minimum reproductive size of organ pipe cactus (Stenocereus thurberi) in southern Arizona. Madrono 34, 294-303.

Piña, H. H., Montaña, C., and del Carmen Mandujano, M. (2007). Fruit abortion in the Chihuahuan-Desert endemic cactus Opuntia microdasys. Plant Ecol. 193, 305-313. doi: 10.1007/s11258-007-9269-x

Reale, L., Sgromo, C., Bonofiglio, T., Orlandi, F., Fornaciari, M., Ferranti, F., et al. (2006). Reproductive biology of Olive (Olea europaea L.) DOP Umbria cultivars. Sex. Plant Rep. 19, 151-161. doi: 10.1007/s00497006-0032-6

Reale, L., Sgromo, C., Ederli, L., Pasqualini, S., Orlandi, F., Fornaciari, M., et al. (2009). Morphological and cytological development and starch accumulation in hermaphrodite and staminate flowers of olive (Olea europaea L.). Sex. Plant Rep. 22, 109-119. doi: 10.1007/s00497-009-0096-1

Rodrigo, J., and Herrero, M. (1998). Influence of intraovular reserves on ovule fate in apricot (Prunus armeniaca L.). Sex. Plant Reprod. 11, 86-93. doi: 10.1007/s004970050124

Rosati, A., Caporali, S., Hammami, S. B., Moreno-Alías, I., Paoletti, A., and Rapoport, H. F. (2012). Tissue size and cell number in the olive (Olea europaea) ovary determine tissue growth and partitioning in the fruit. Funct. Plant Biol. 39, 580-587. doi: 10.1071/FP12114

Rosati, A., Caporali, S., Paoletti, A., and And Famiani, F. (2011). Pistil abortion is related to ovary mass in olive (Olea europaea L.). Sci. Hortic. 127, 515-519. doi: 10.1016/j.scienta.2010.12.002

Rosati, A., Zipanćiè, M., Caporali, S., and Padula, G. (2009). Fruit weight is related to ovary weight in olive (Olea europaea L.). Sci. Hortic. 122, 399-403. doi: 10.1016/j.scienta.2009.05.034

Thompson, M. M. (1967). "Role of pollination in nut development," in Proceedings of the Nut Growers Society of Oregon, Vol. 53. (Washington, DC; British Columbia), 31-36.

Thompson, M. M., Lagerstedt, H. B., and Mehlenbacher, S. A. (1996). "Hazelnuts," in Fruit Breeding: Nuts, Vol. 3 eds J. Janick and J. N. Moore (New York, NY: Wiley), 125-184.

Conflict of Interest Statement: The authors declare that the research was conducted in the absence of any commercial or financial relationships that could be construed as a potential conflict of interest.

Received: 03 August 2014; accepted: 17 September 2014; published online: 06 October 2014.

Citation: Liu J, Zhang H, Cheng Y, Wang J, Zhao Y and Geng W (2014) Comparison of ultrastructure, pollen tube growth pattern and starch content in developing and abortive ovaries during the progamic phase in hazel. Front. Plant Sci. 5:528. doi: $10.3389 /$ fpls.2014.00528

This article was submitted to Crop Science and Horticulture, a section of the journal Frontiers in Plant Science.

Copyright (c) 2014 Liu, Zhang, Cheng, Wang, Zhao and Geng. This is an openaccess article distributed under the terms of the Creative Commons Attribution License (CC BY). The use, distribution or reproduction in other forums is permitted, provided the original author(s) or licensor are credited and that the original publication in this journal is cited, in accordance with accepted academic practice. No use, distribution or reproduction is permitted which does not comply with these terms. 